\title{
Avastec: Ambiente Virtual de Aprendizagem em Sistema de Telefonia Celular
}

\author{
Carlos G. Fontinelle, Laura Michaella B. Ribeiro, Vitor Bremgartner \\ Instituto Federal do Amazonas (IFAM) - Campus Manaus Distrito Industrial \\ Av. Danilo Areosa - Distrito Industrial - 69075-351 - Manaus - AM - Brasil \\ \{fontinelle, laurarb\}@ifam.edu.br, vitorbref@gmail.com
}

\begin{abstract}
This paper presents a Virtual Learning Environment, Avastec, to support classroom teaching the discipline of Cellular Mobile Telephony for Technology and Engineering Courses. To achieve this goal, we used the Moodle platform. The methodology used was the application of quantitative and qualitative research to practical use within this virtual teaching environment, where employees were questionnaires and evaluation activities electronically. It was found that a classroom discipline planned in view of the Moodle platform has several advantages, one of which, the optimization of time in the classroom and the composition of classes more dynamic.
\end{abstract}

Resumo. Este trabalho apresenta um Ambiente Virtual de Aprendizagem, o Avastec, para apoio ao ensino presencial da disciplina de Telefonia Móvel Celular de Cursos Superiores de Tecnologia e Engenharia. Para atingir este objetivo, foi utilizada a plataforma Moodle. A metodologia empregada foi à aplicação de uma pesquisa quanti-qualitativa de uso prático dentro deste ambiente virtual de ensino, onde foram empregados questionários e atividades avaliativas de forma eletrônica. Constatou-se que uma disciplina presencial planejada na perspectiva da plataforma Moodle apresenta diversas vantagens, sendo uma delas a otimização do tempo em sala de aula e a composição de aulas mais dinâmicas.

\section{Introdução}

Segundo [BREMGARTNER et al., 2015], os modelos de Educação à Distância (EaD) e presencial, que anteriormente eram distintos, atualmente se mesclam e resultam numa nova situação de ensino presencial apoiado pelo ensino à distância também conhecido por blended learning. Nesta nova modalidade de ensino, a EaD e o ensino presencial se complementam e se fundem para que as facilidades do ensino à distância sejam trazidas para sala de aula e a experiência da interação e proximidade de professores e alunos em sala de aula seja levado para o ambiente à distância. Em um Ambiente Virtual de Aprendizagem (AVA), os principais componentes são subsistemas que organizam conteúdos, acompanham atividades, avaliam o processo de ensino-aprendizagem, fornecem suporte online ao aluno e comunicação eletrônica.

Neste contexto, o objetivo deste trabalho foi desenvolver um ambiente virtual de ensino na plataforma Moodle [MOODLE, 2016] para apoio à aprendizagem do sistema de telefonia celular com ênfase na tecnologia celular 4G/LTE [4G/LTE, 2016] para os 
estudantes da disciplina Comunicações Móveis do Curso de Tecnologia em Sistemas de Telecomunicações (TST) de uma Instituição de Ensino (IE).

O ambiente virtual de ensino proposto é constituído de um conjunto de módulos que abordam os diversos conteúdos da disciplina de Telefonia Móvel Celular de cursos superiores de telecomunicações, fornecendo ao usuário uma interface gráfica interativa padronizada. Este ambiente de ensino foi denominado de Ambiente Virtual de Aprendizagem em Sistema de Telefonia Celular (Avastec).

\subsection{Motivação}

A Telecomunicação é uma área fascinante e ao mesmo tempo complexa. São poucas as pessoas que se propõem a estudar e entender seus conceitos teóricos e suas características práticas, isso ocorre pelo fato de na maioria das vezes nos depararmos com textos herméticos e com poucos exemplos que apresentem os conceitos teóricos de forma clara.

Com o avanço tecnológico e o desenvolvimento da telefonia móvel celular foram desenvolvidas técnicas de modulação e codificação digital que aumentaram a capacidade de transmissão e recepção das informações o que tornou o uso do telefone celular economicamente viável.

O uso de ferramentas pedagógicas que disponibilizam a visualização de imagens, animações gráficas, vídeos, jogos e interações entre os alunos, possibilita um melhor entendimento da disciplina, uma vez que além do uso da "imaginação" e longos cálculos, o aluno pode obter um contexto mais próximo da realidade e dos conceitos concretos do assunto que está sendo ministrado.

É essencial que os discentes de cursos superiores da área de telecomunicações estejam familiarizados com esses conceitos teóricos e os coloquem em prática por meio de ferramentas que facilitem o entendimento da tecnologia da telefonia móvel celular, principalmente as redes móveis celulares de última geração, LTE/4G, uma vez que este estudo apresenta alta dinamicidade.

\section{Trabalhos Correlatos}

Existem diversos trabalhos que abordam a utilização de AVAs e demonstram suas vantagens de utilização.

O trabalho de [PEREIRA, 2009] descreve a experiência vivenciada com o Moodle, utilizando essa tecnologia na aprendizagem da disciplina Introdução à Engenharia de Produção para o Curso de Bacharelado em Engenharia de Produção Civil da Universidade do Estado da Bahia - UNEB. Com foco na utilização dessa ferramenta de apoio ao processo ensino aprendizagem, onde o conteúdo foi apresentado e discutido presencialmente em sala de aula e à distância através de exercícios. O estudo de caso permitiu descrever o uso desse ambiente virtual de ensino e verificar a aceitação da modalidade de EaD pelos alunos.

[ONOFRE, 2010] relata a construção, aplicação e avaliação de um AVA como ferramenta auxiliar ao ensino de Física com metodologia tradicional, no Ensino Médio, usando a plataforma Moodle. O ambiente foi estruturado para que o aluno faça uso do AVA da primeira à última semana do ano letivo, com uma estrutura distribuída por ciclos para as três séries do Ensino Médio. Os ciclos possuem uma estrutura que 
V Congresso Brasileiro de Informática na Educação (CBIE 2016)

Anais dos Workshops do V Congresso Brasileiro de Informática na Educação (CBIE 2016)

consiste em uma orientação de estudos, um texto resumo com exercícios para assimilação e aprofundamento, laboratórios virtuais, simuladores e questionários avaliativos.

Em seu artigo, [FONSECA et al.,2012] apresenta a aplicação de um AVA com material didático multimídia para apoio ao ensino presencial da disciplina de Processamento Digital de Sinais (PDS) e Wavelets em cursos de Tecnologia e Engenharia ligadas à área de Eletrônica, Mecatrônica e Informática. $\mathrm{O}$ ambiente foi criado utilizando-se a Plataforma Moodle.

Já o trabalho desenvolvido por [ANJOS, 2014] faz referência à experiência vivenciada na Universidade Federal de Mato Grosso, relativa ao processo de implantação dos AVAs para os cursos presenciais da instituição.

Este autor ainda apresentou um detalhamento das etapas realizadas para a consecução dos AVAs, como o planejamento de infraestrutura, a integração dos Ambientes com o Sistema Acadêmico da Universidade, o Design do Ambiente Virtual, bem como pormenorizou o processo de capacitação realizado com os professores, relativo à utilização desses Ambientes, apresentando dados parciais dos Institutos e Faculdades que participaram das capacitações, o que de certa forma, retrata o nível de aceitação ou possível rejeição desse recurso.

O artigo de [SANTANA et al, 2014] avaliou o uso das ferramentas educacionais do AVA Moodle e o impacto das mesmas sobre o desempenho dos estudantes nas disciplinas.

[GOULARTE et al, 2014] propôs um método de sumarização de texto para automatizar parte do processo de correção das atividades dissertativas de um AVA.

Um sistema multiagente foi utilizado por [LIMA et al, 2014] para caracterizar as interações sociais entre os estudantes que ocorrem nos fóruns e nas mensagens de um AVA e apresentou essas informações ao professor sob a forma de sociograma ou tabela.

O trabalho desenvolvido por [SOUZA et al, 2015] fez uso de técnicas de exploração de dados (estatística multivariada) como apoio à avaliação de atividades desenvolvidas em um AVA para discentes de um curso da Universidade Federal do Ceará (UFC).

\section{Ambiente Avastec}

A metodologia utilizada para alcançar os objetivos desse trabalho foi a aplicação de uma pesquisa quanti-qualitativa e prática na comunidade acadêmica (corpo docente, corpo discente, equipe pedagógica e equipe técnica) do Curso Superior em Tecnologia de Sistemas de Telecomunicações (TST) de uma Instituição Federal de Ensino (IFE). Trata-se de uma ferramenta tecnológica aplicada na educação e aprendizagem à distância, desenvolvida em Moodle e disponibilizada para verificar a opinião da comunidade acadêmica da IFE a respeito da utilização desse ambiente de ensino.

Dos 25 estudantes matriculados na disciplina Comunicações Móveis do curso de TST, a população analisada foi composta por 17 alunos que frequentam regularmente essa disciplina. A Figura 1 ilustra o fluxograma dos percursos metodológicos, constituídos por sete blocos que foram traçados para consecução do trabalho. 
V Congresso Brasileiro de Informática na Educação (CBIE 2016)

Anais dos Workshops do V Congresso Brasileiro de Informática na Educação (CBIE 2016)

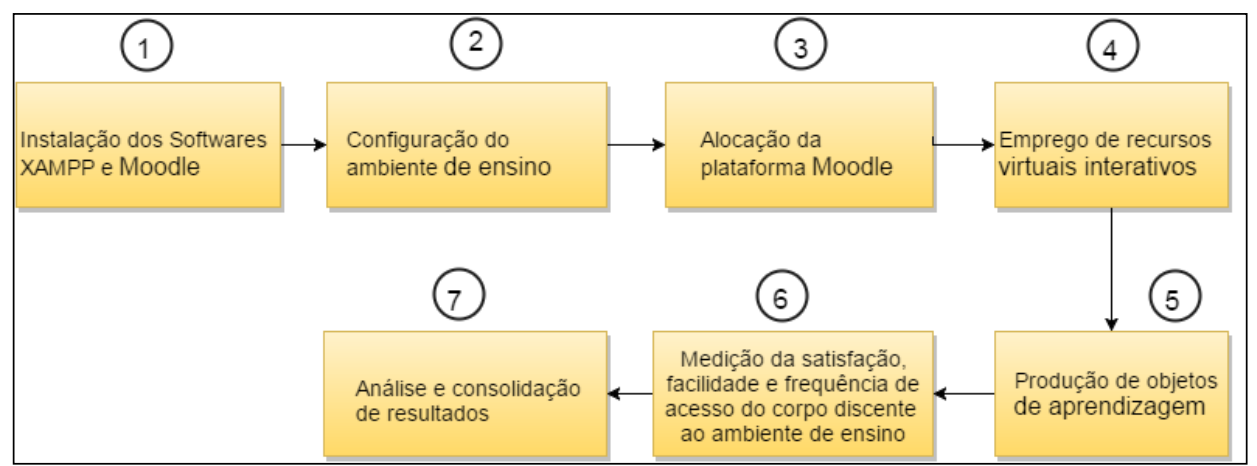

Figura 1. Fluxograma de desenvolvimento do Avastec.

Os sete blocos dos percursos metodológicos ilustrados na Figura 1 são:

\section{BLOCO 1: INSTALAÇÃO DOS SOFTWARES XAMPP e MOODLE}

Nesta etapa, foram instalados os softwares XAMPP e o Moodle em um computador pessoal do autor (PC com sistema operacional Windows de 64 bits) que funcionou como host interno (servidor local).

O XAMPP é um conjunto de ferramentas open source multiplataforma, ou seja, pode funcionar em quatro sistemas operacionais: Windows, Linux, Mac OS X ou Solaris. É composto pelo servidor de páginas para web PHP, o banco de dados MySQL e o servidor web Apache. O ambiente Moodle instalado possui versão 2.9+.

\section{BLOCO 2: CONFIGURAÇÃO DO AMBIENTE DE ENSINO}

Foram inseridos recursos (arquivos, pastas, URL, páginas, entre outros) e atividades (base de dados, fóruns, glossários, textos, wiki, vídeos, lições, pesquisas de avaliação, questionários, animações gráficas, entre outros) do Moodle para modelar o ambiente de ensino de acordo com o conteúdo programático da disciplina Comunicações Móveis da Instituição de Ensino, além de inserir e remover blocos, com informações sobre participantes, últimas notícias, calendários, entre outros.

\section{BLOCO 3: ALOCAÇÃO DA PLATAFORMA MOODLE} ensino.

Foi utilizado um host externo (servidor externo) para hospedar o ambiente de

\section{BLOCO 4: EMPREGO DE RECURSOS VIRTUAIS INTERATIVOS}

Foram empregados os recursos interativos do programa Hot Potatoes (versão 6) para elaborar atividades avaliativas e as mesmas foram exportadas para o ambiente de ensino desenvolvido.

O Hot Potatoes é um software gratuito educacional canadense utilizado para criar exercícios sob a forma de objetos digitais para publicação na web (múltipla escolha, palavras cruzadas, associação de colunas, preenchimento de lacunas, análise de sentenças: verdadeiro ou falso).

\section{BLOCO 5: PRODUÇÃO DE OBJETOS DE APRENDIZAGEM}

Foi usado o programa Microsoft PowerPoint 2010 como recurso para criação de animações gráficas e as mesmas foram exportadas para o ambiente de ensino 
V Congresso Brasileiro de Informática na Educação (CBIE 2016)

Anais dos Workshops do V Congresso Brasileiro de Informática na Educação (CBIE 2016)

desenvolvido.

\section{BLOCO 6: MEDIÇÃO DA SATISFAÇÃO, FACILIDADE E FREQUÊNCIA DE ACESSO DO CORPO DISCENTE AO AMBIENTE DE ENSINO}

Os instrumentos de avaliação (questionários online, avaliação de reação de curso e entrevistas) foram aplicados ao corpo discente, corpo docente, equipe pedagógica e equipe técnica (analistas e desenvolvedores de sistema) da instituição de ensino para obter o feedback dos profissionais envolvidos na disciplina.

\section{BLOCO 7: ANÁLISE E CONSOLIDAÇÃO DE RESULTADOS}

Nesta última etapa, foi realizada a análise de dados e a consolidação dos resultados por meio de análise estatística, gráficos e tabelas.

No ambiente Avastec, alunos, professores, tutores e administradores escolares são usuários do sistema. Assim, o primeiro passo foi cadastrá-los no ambiente de ensino. Alguns conteúdos didáticos e/ou atividades foram inseridos no ambiente para torná-lo mais diversificado e interativo que permitiu maior desenvolvimento do ensinoaprendizagem.

A Figura 2 apresenta a tela de acesso ao ambiente de ensino.

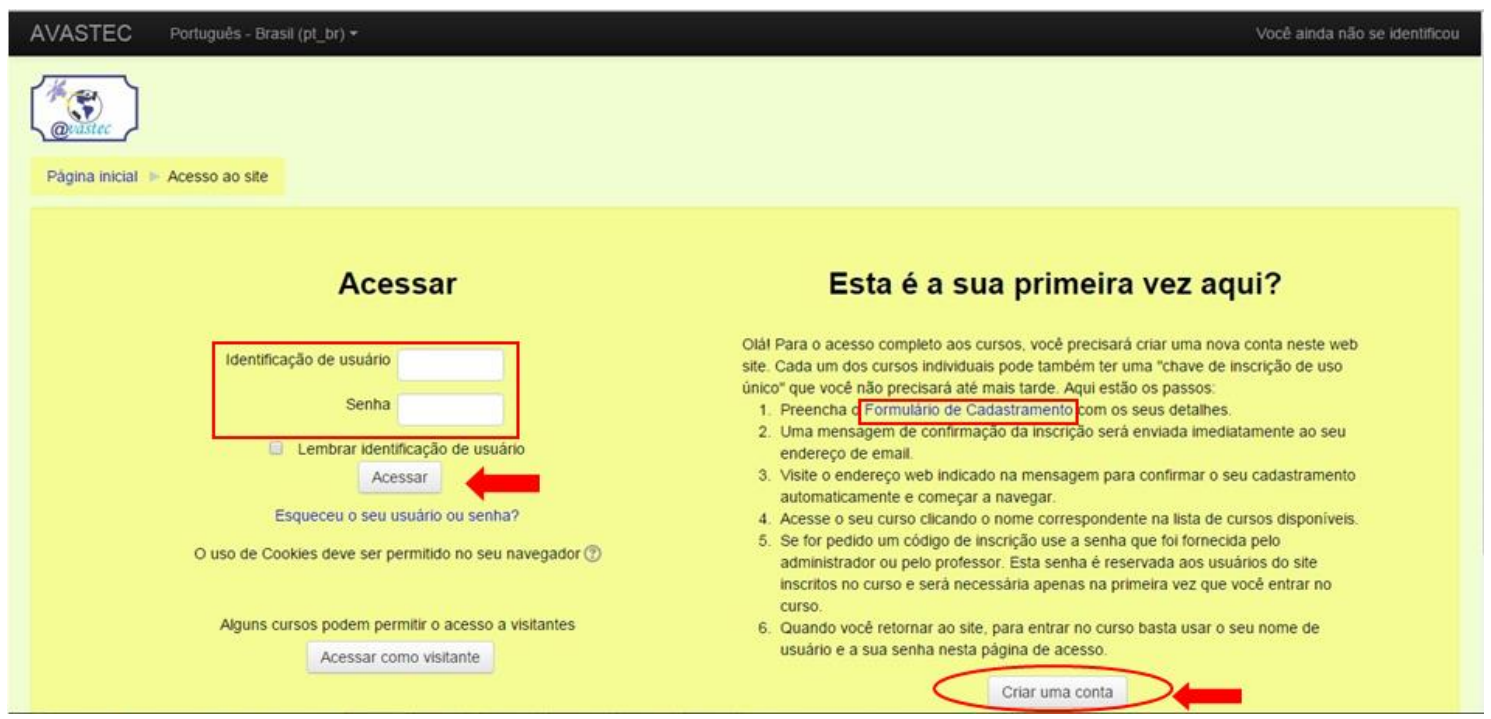

Figura 2. Página de acesso ao ambiente.

Para iniciar o seu aprendizado no ambiente Avastec, o aluno deve, primeiramente, acessar o web site, por meio do endereço eletrônico "avastec.esy.es" digitado no campo de endereços do seu navegador de internet (web browser), conforme ilustra a Figura 2. Em seguida, a página de acesso ao Avastec será mostrada.

$\mathrm{O}$ administrador do Avastec fez o cadastro manual e a inscrição de cada usuário no ambiente e enviou, via e-mail, o login de usuário e senha padrão para que cada um pudesse acessar a disciplina disponibilizada no ambiente.

Ainda com relação à Figura 2, por exemplo, quando o discente quiser acessar o ambiente, basta digitar no campo "identificação de usuário" seu número de matrícula do IFE e no campo "senha" a senha padrão fornecida pelo professor e clicar no botão "Acessar". Existe, também, a possibilidade do usuário acessar o ambiente como visitante desde que o administrador do sistema permita e informe ao visitante a senha de 
V Congresso Brasileiro de Informática na Educação (CBIE 2016)

Anais dos Workshops do V Congresso Brasileiro de Informática na Educação (CBIE 2016)

acesso, bem como possui opções de cadastramento (lado direito, parte superior e inferior da tela).

A Figura 3 ilustra uma atividade interativa em que foi usado o programa $\mathrm{Hot}$ Potatoes [HOT POTATOES, 2016]. Essa atividade consistiu em fazer um jogo de palavras cruzadas com os assuntos abordados no Módulo 3 da disciplina. Nas palavras cruzadas, foram realizadas perguntas na qual a resposta deveria ser colocada no local numerado. Esse aplicativo também disponibiliza pistas e verifica as respostas. É possível visualizar os recursos oferecidos por este aplicativo: cronometrar a atividade, parar a qualquer momento e obter a nota obtida. Ao término da atividade, é possível obter um relatório detalhado contendo: identificação do usuário, nota mais alta obtida, número de tentativas, a data em que foi realizada a atividade e o tempo que levou para concluir a atividade.

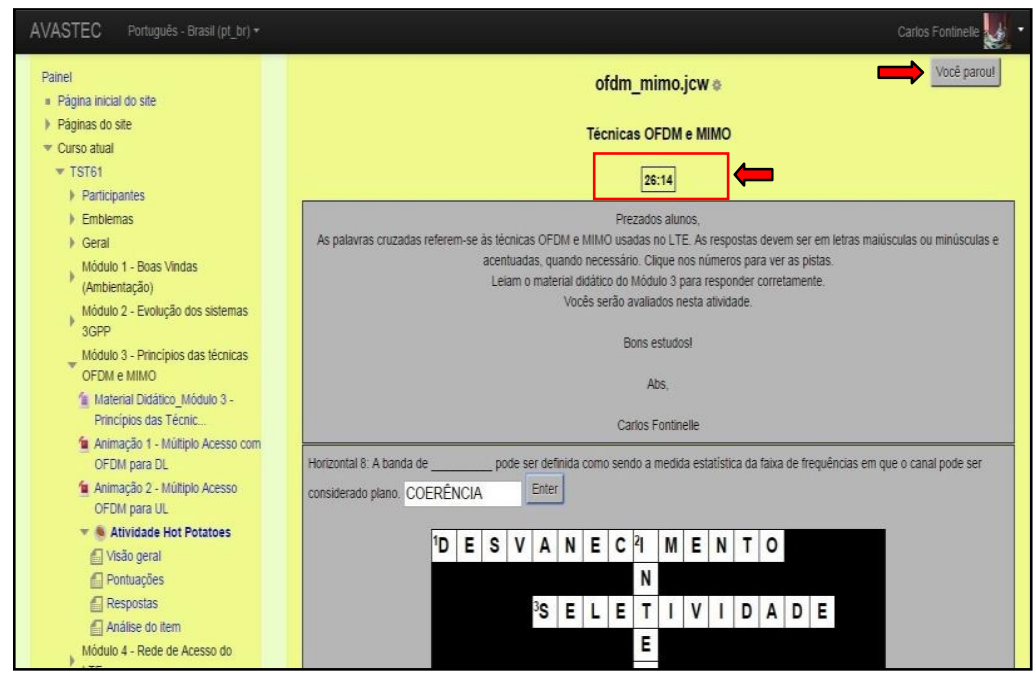

Figura 3. Atividade realizada com Hot Potatoes.

Uma animação gráfica foi produzida em software de apresentação de slides (com extensão .ppt) para explicar um conceito importante da tecnologia 4G/LTE (Processo HARQ no LTE), conforme é mostrada na Figura 4.

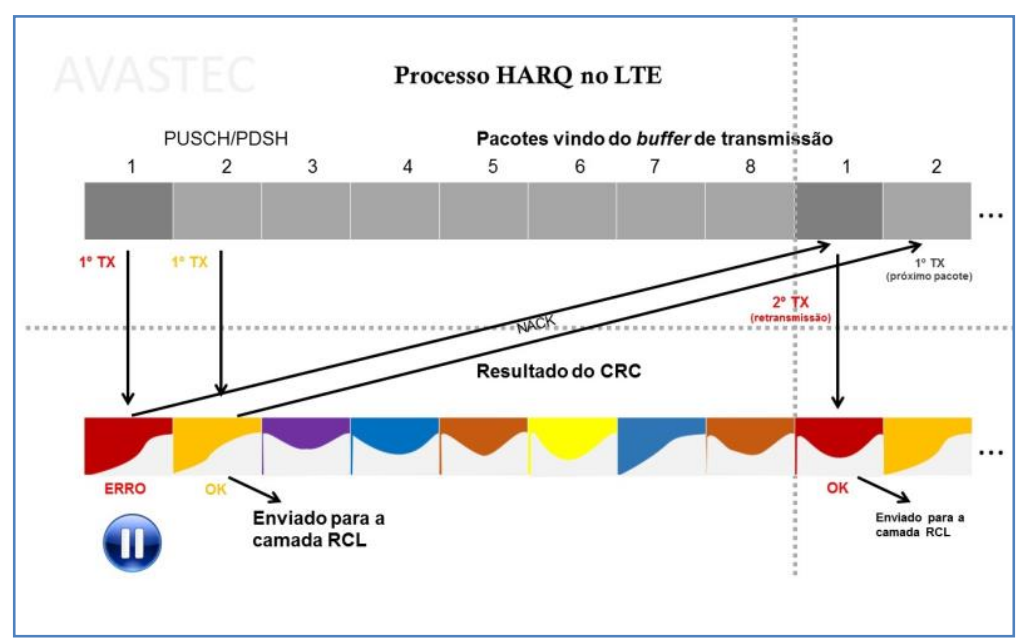

Figura 4. Explicação de conceito da tecnologia 4G/LTE. 
V Congresso Brasileiro de Informática na Educação (CBIE 2016)

Anais dos Workshops do V Congresso Brasileiro de Informática na Educação (CBIE 2016)

\section{Resultados e Análise de dados}

Para melhor embasamento da análise dos dados, as pesquisas foram realizadas por meio de questionamentos e entrevistas aos acadêmicos, professores e pedagogos.

Citam-se, a seguir, algumas opiniões de integrantes da comunidade acadêmica que acessaram e usaram o ambiente: "Sentimo-nos atraídos em poder nos organizar através do ambiente Moodle, que proporciona aulas mais interativas, onde o aluno pode construir sua aprendizagem com acréscimos intelectuais à sua formação e do grupo". (Pedagoga - IFAMCMDI); "Pareceu-me que o ambiente criado foi muito bem organizado, disponibilizando um considerável número de recursos, possibilitando a criação de um AVA de qualidade, fácil acesso e navegação com atividades variadas e atraentes" (Professor - Curso TST do IFAMCMDI) e "O Avastec contempla grande quantidade de ferramentas, é bem estruturado, adequado ao ensino à distância" (Aluno - disciplina Comunicações Móveis - Curso TST do IFAM-CMDI).

Outro aspecto abordado foi sobre a avaliação do curso à distancia, por meio do ambiente Moodle, em relação à aprendizagem.

As exposições, em geral, dos alunos podem ser resumidas assim: " $\mathrm{O}$ ambiente Moodle, são ferramentas que podem contribuir muito para a aprendizagem, depende do conhecimento que o indivíduo possui sobre seu funcionamento." (Aluno - disciplina Comunicações Móveis - Curso TST do IFAM-CMDI).

Ficou claro nos comentários dos alunos que um dos aspectos mais importantes que influenciam no processo de aprendizagem é a interação dos atores envolvidos no processo.

Apresentam-se a seguir alguns resultados obtidos na análise do questionário de pesquisa respondido pelos alunos da disciplina Comunicações Móveis do Curso TST do IFAM-CMDI, onde as respostas e a construção dos gráficos foram consolidadas por meio de ferramentas estatísticas disponíveis no programa Microsoft Office Excel.

Após a coleta e análise dos dados, foram obtidos os seguintes resultados:

a) $\mathrm{Na}$ figura 5, verificou-se que aproximadamente 70,6\% dos dezessete alunos matriculados na disciplina Comunicações Móveis do Curso TST do IFAM-CMDI nunca tiveram experiência em situações de ensino à distância, ou seja, apenas cinco alunos (aproximadamente 29,4\%) já participaram de cursos EaD. É necessário motivar e orientar os alunos à participação em AVAs.

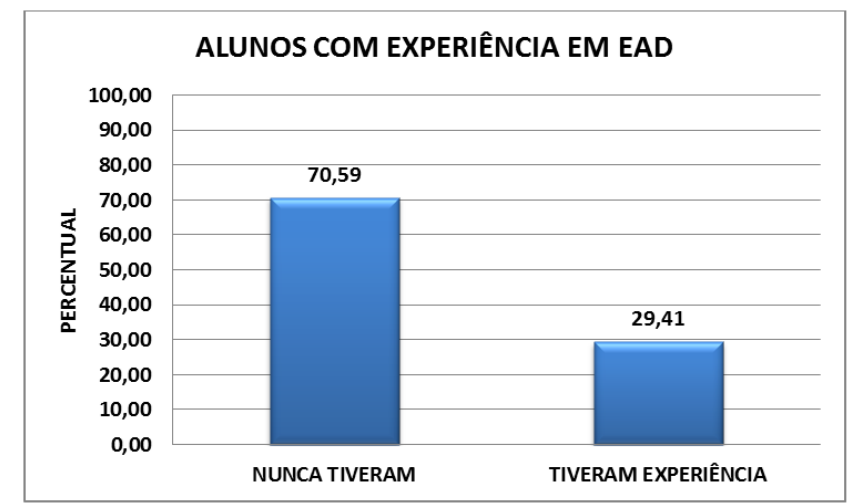

Figura 5 - Alunos com experiência em EaD.

b) Constatou-se que os cinco (100\%) professores do Curso TST do IFAM-CMDI nunca utilizaram o Moodle com repositório de materiais em sua prática pedagógica. É 
V Congresso Brasileiro de Informática na Educação (CBIE 2016)

Anais dos Workshops do V Congresso Brasileiro de Informática na Educação (CBIE 2016)

necessário capacitar o corpo docente para manuseio e/ou desenvolvimento de um ambiente virtual de ensino.

c) Aproximadamente $58,9 \%$ dos alunos matriculados na disciplina Comunicações Móveis do Curso TST do IFAM-CMDI responderam satisfatoriamente e em tempo hábil as atividades (exercícios, avaliações, participação em fóruns) que lhes foram impostas, ou seja, apenas sete alunos (41,1\%) não realizaram todas essas atividades, conforme pode ser visualizado na figura 6 .

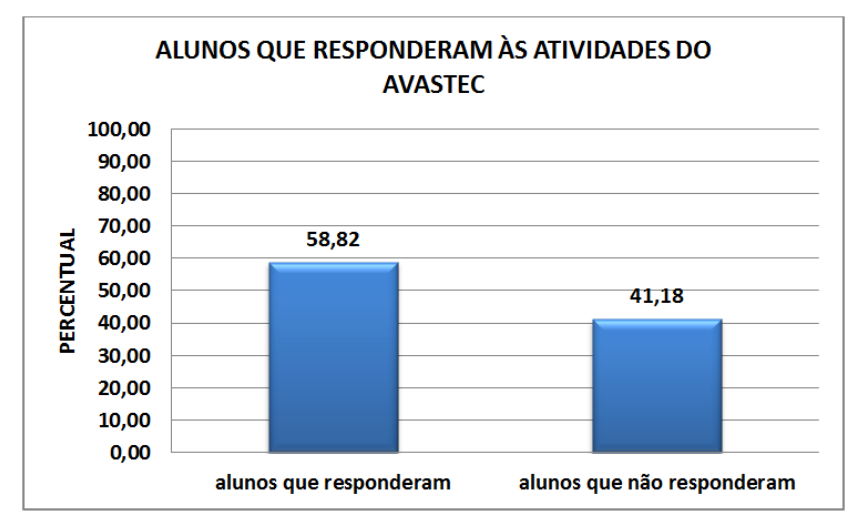

Figura 6 - Alunos que responderam as atividades do Avastec.

Buscou-se a opinião dos alunos sobre as ferramentas do Avastec mais eficientes na transmissão e fixação dos conteúdos da disciplina Comunicações Móveis do Curso TST do IFAM-CMDI.

$\mathrm{Na}$ figura 7 são apresentados os resultados dos alunos sobre a resolução dos exercícios de fixação. Verificou-se que nove alunos (aproximadamente 53\%) sempre tentaram fazer os exercícios de fixação propostos.

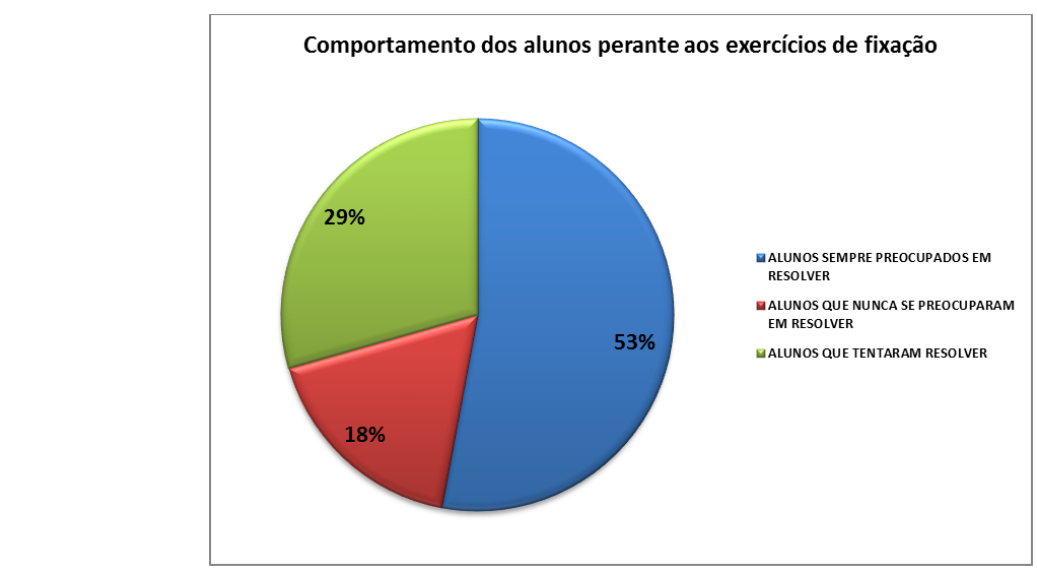

Figura 7 - Comportamento dos alunos durante as atividades no Avastec.

Analisou-se a participação dos alunos da disciplina Comunicações Móveis do Curso TST do IFAM-CMDI em relação ao uso do Fórum.

Apenas 59\% (dez alunos) tiveram uma frequência de acesso média ao ambiente para participar dos fóruns, conforme mostra a figura 8. Isso se deve ao pouco tempo que os alunos tiveram para ler os materiais didáticos teóricos disponíveis no ambiente e/ou realizar pesquisas, fins de obter conhecimentos suficientes para debater suas ideias com os demais colegas. 


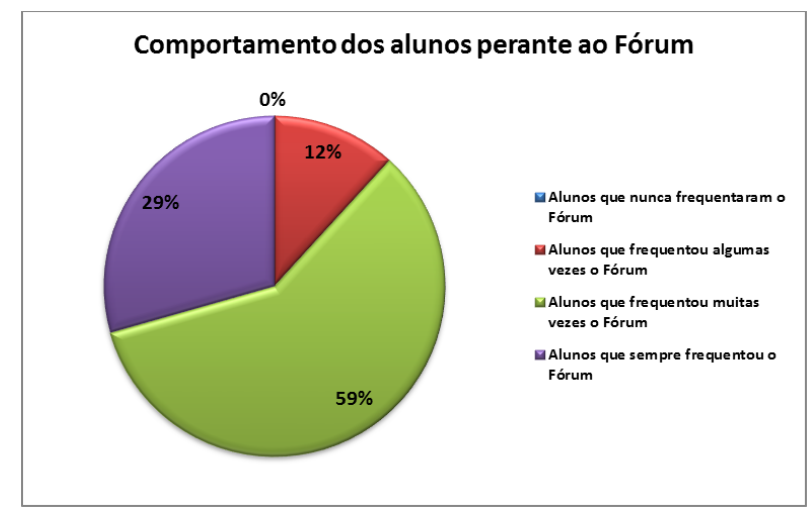

Figura 8 - Comportamento dos alunos durante as discussões no Fórum.

\section{Conclusões}

Neste artigo foi apresentada a análise e avaliação da estrutura e organização do Avastec a ser utilizado pela IFE como recurso virtual de ensino e apoio às aulas presenciais da disciplina Comunicações Móveis. Foi possível compreender as necessidades dos alunos no tocante aos conceitos e assuntos de difícil compreensão da disciplina e vislumbraram-se possíveis melhorias no aprendizado por meio de aplicações de recursos pedagógicos tais como criação de animações gráficas, vídeos, jogos e debate dos assuntos por meio de fóruns, amparadas nas opiniões coletadas. $\mathrm{O}$ sistema implantado deve ser útil tanto para o ensino em sala de aula ou laboratório de Informática, bem como para o aprendizado autônomo.

$\mathrm{O}$ instrumento de pesquisa que serviu como ferramenta de avaliação mostrou-se válido e viável, pois através do mesmo foi realizada a análise e avaliação da estrutura e organização do Avastec a ser utilizado pelo IFAM-CMDI como recurso virtual de ensino e apoio às aulas presenciais da disciplina Comunicações Móveis.

A partir do uso desse ambiente virtual de ensino, constatou-se que houve uma maior facilidade dos alunos na assimilação dos conceitos e conteúdos referentes à área de telefonia móvel celular, bem como do professor na transmissão desses conhecimentos. Também novos alunos e/ou professores sentiram-se motivados em utilizar esta ferramenta pedagógica. Essas expectativas com relação aos corpos discente e docente também devem ser motivadas pelos corpos técnico e pedagógico da IFE.

Como trabalhos futuros, sugere-se que os professores desenvolvam ambientes virtuais de ensino para apoio às aulas presenciais de outras disciplinas do Curso TST da IFE, tais como: Processamento Digital de Sinais, Comunicação Digital e Princípios de Telecomunicações. Outra sugestão seria dispor de uma solução compartilhada de acesso a um laboratório remoto, a partir da plataforma Moodle, onde o aluno poderia controlar seus experimentos à distância.

\section{Referências}

4G/LTE; (2016). 4G vs LTE - What is the difference? http://www.androidauthority.com/4g-vs-lte-274882/

ANJOS, R. A. V. dos.; AlONSO, K. M.; ANJOS, A. M. dos. A Implantação de Ambientes Virtuais de Ensino para os Cursos Presenciais da Universidade Federal de 
V Congresso Brasileiro de Informática na Educação (CBIE 2016)

Anais dos Workshops do V Congresso Brasileiro de Informática na Educação (CBIE 2016)

Mato Grosso. In: ESUD 2014 - IX Congresso Brasileiro de Ensino Superior à Distância, Florianópolis-SC, ago. 2014. Acesso em: 23 dez. 2015.

BREMGARTNER, V.; NETTO, J.M.; MENEZES, C. S. (2015). Explorando arquiteturas pedagógicas recomendadas por meio de agentes e ontologia de modelo do aluno em ambientes virtuais de aprendizagem. Anais do XXVI Simpósio Brasileiro de Informática na Educação, Maceió, AL.

FONSECA, E. S. et al. Aplicação de Ambiente Virtual de Aprendizagem como Auxílio ao Ensino Presencial de Processamento Digital de Sinais e Wavelets. Sinergia, São Paulo, v.13, p. 143-152, maio/ago. 2012. Acesso em: 13 jan. 2016.

HOT POTATOES. (2016). Hot Potatoes Home Page, https://hotpot.uvic.ca/

MOODLE (2016) A Free, Open Source Course Management System for Online Learning, www.moodle.org/

ONOFRE, D. C. de. Escolanet: o uso do Ambiente Virtual de Vprendizagem (AVA) como ferramenta de apoio e estímulo à aprendizagem de Física no Ensino Médio. 2010. 106f. Dissertação (Mestrado em Física), Universidade Federal de São Carlos, São Carlos, 2010. Acesso em: 05 out. 2014.

PEREIRA, T.R.D.S.; FILHO, A.B.G.; ANJOS, T.D.S. dos. O Moodle como Ferramenta de Apoio à Aprendizagem na Disciplina Introdução à Engenharia de Produção no Curso de Engenharia de Produção Civil da UNEB. In: COBENGE 2009, Recife-PE, 2009. Acesso em: 22 jan. 2016.

GOULARTE, F. B et al. (2014).Métricas de sumarização automática de texto em tarefas de um Ambiente Virtual de Aprendizagem. Programa de Pós-Graduação em Ciência da Computação. Universidade Federal de Santa Catarina (UFSC). III Congresso Brasileiro de Informática na Educação (CBIE 2014). XXV Simpósio Brasileiro de Informática na Educação (SBIE 2014). Dourados-MS.

LIMA, D.P.R. de. et al. (2014).Um Sistema Multiagente que Caracteriza as Relações Sociais entre Alunos de um Ambiente Virtual de Aprendizagem. Instituto de Computação. Universidade Federal do Amazonas (UFAM). III Congresso Brasileiro de Informática na Educação (CBIE 2014). XXV Simpósio Brasileiro de Informática na Educação (SBIE 2014). Dourados, MS.

SANTANA, M.A. (2014). Avaliando o Uso das Ferramentas Educacionais no Ambiente Virtual de Aprendizagem Moodle. Instituto de Computação. Universidade Federal de Alagoas (UFAL). III Congresso Brasileiro de Informática na Educação (CBIE 2014). XXV Simpósio Brasileiro de Informática na Educação (SBIE 2014). Dourados, MS.

SOUZA, T.I.A. et al.(2015). Aplicação de Técnicas de Exploração de Dados como Apoio a Avaliação de Atividades Desenvolvidas em um Ambiente Virtual de Aprendizagem (AVA). Programa de Pós-Graduação em Engenharia de Teleinformática. Universidade Federal do Ceará (UFC). IV Congresso Brasileiro de Informática na Educação (CBIE 2015). Maceió, AL. 